\title{
Commentary
}

\section{An Ethical Argument for Integrated Palliative Care}

\section{Shay Beider}

\author{
The Heart Touch Project, Santa Monica, CA 90405, USA
}

'In the midst of life, we are in death'
from The Book of Common Prayer

The Palliative Care, or comfort care, movement in the USA is on the rise. Currently, palliative services are not integrated in an organized way throughout healthcare. If we accept the argument that palliative care is ethically desirable and that all patients are entitled to palliative services regardless of a terminal diagnosis, it follows that it needs to be integrated across a wide range of healthcare services. Ethical questions regarding palliative care and well-known ethical frameworks are discussed and an argument is made for integrating palliative healthcare services throughout the healthcare system and not simply at the end of life. Complementary and alternative medicine (CAM) therapies are discussed as useful and necessary components of palliative care. If we as a society look beyond separating cures and palliation, we will come closer to incorporating compassionate care throughout the disease process.

Keywords: comfort - pain management - quality of life - end of life - well-being

\section{Introduction}

The palliative care, or comfort care, movement in the USA is on the rise (1). Over the last several years, hospitals have developed comfort and pain management programs that support minimizing pain and maximizing comfort for their patients. Accrediting institutions, such as the Joint Commission on Acceditation of Healthcare Organization (JCAHO), have mandated standards for pain assessment and management for hospitals, nursing homes and other facilities (2).

The philosophical underpinnings of the palliative care movement come from the hospice movement, which arose in the UK in the 1960s and spread to the USA in the 1970s. Patient demand for these services then moved the trend for palliative services forward. This latter response can be viewed as a reflection of the patient empowerment processes emanating from the consumer rights and civil rights movements of the 1960s and 1970s.

For reprints and all correspondence: Shay Beider, The Heart Touch Project, Director of the Children's Program, 3400 Airport Ave., Suite 42,

Santa Monica, CA 90405, USA. Tel: +1-310-391-2558 ext. 4;

Fax: +1-310-391-2168; E-mail: shay@hearttouch.org
However, our human actions do not currently include the integration of palliative services in an organized way throughout healthcare. In this commentary, I propose that we accept the argument that palliative care is ethically desirable and, as such, it needs to be integrated across a wide range of healthcare services. I consider basic ethical questions regarding palliative care, and I utilize well-known ethical frameworks to argue for the proposed concept of 'integrated palliative healthcare services' throughout the healthcare system in the USA. I also look at complementary and alternative medicine (CAM) therapies that are useful and necessary components of palliative care. I have chosen to focus on the USA because it is in a state of transition regarding palliative care services. However, it is important to acknowledge that internationally other countries have already embraced a more integrative approach to palliative care.

\section{Defining Palliative Care}

The World Health Organization has defined palliative care as 'the active, total care of patients whose disease is not responsive to curative treatment' (3). Eileen Chrystal-Frances has written 'Palliative care of the terminally and chronically ill is a specialized field of medicine that is slowly emerging in step with

(C) The Author (2005). Published by Oxford University Press. All rights reserved.

The online version of this article has been published under an open access model. Users are entitled to use, reproduce, disseminate, or display the open access version of this article for non-commercial purposes provided that: the original authorship is properly and fully attributed; the Journal and Oxford University Press are attributed as the original place of publication with the correct citation details given; if an article is subsequently reproduced or disseminated not in its entirety but only in part or as a derivative work this must be clearly indicated. For commercial re-use, please contact journals.permissions@oupjournals.org 
certain changes in our society and our mindset toward death and dying' (4). She describes the interdisciplinary approach of palliative care and its emphasis on pain management and attention to psychological, social and spiritual issues. The goal of palliative care is to attain the optimal quality of life for patients. Thus, palliative care encompasses multiple concepts of pain management, quality of life and comfort care. The latter is a state linked to outcomes such as ease, well-being and satisfaction (5).

Palliative care embraces the hospice philosophy of care and strives to expand this concept to include patients who experience pain or discomfort, but who do not necessarily qualify for hospice services. Thomas Hoyer argues that today's end of life efforts are 'a repudiation of the notion that 'hospice' care is a choice to be made at the end-of-life' (6). He contends that it is instead a movement dedicated 'to making the healthcare system so responsive to quality of life concerns as to make hospice care unnecessary as an alternative (even if useful as an adjunct) to that system' (6). Thomas Hoyer is suggesting a notion of palliative care as an aspect of healthcare for all patients and not simply for those nearing the end of life. As such, it implies that all patients are entitled to palliative services regardless of a terminal diagnosis.

\section{Ethical Frameworks}

Why might such an integrated palliative healthcare system be ethically meaningful? Four moral principles are frequently utilized as a framework for principles of bioethics: respect for autonomy, beneficence, non-maleficence and justice. In their description of beneficence, Beauchamp and Walters write that many medical codes assert the health professional's 'primary commitment is to protect the patient from harm and to promote the patient's welfare' (7). Palliative care can protect patients from the harm of experiencing symptoms of pain, and it can promote patient welfare by enhancing well-being. Historically, beneficence includes the active promotion of good, kindness and charity; however, modern notions have tended to focus more on removing possible harms (7). Palliative care harks back to an earlier concept of healing that includes caring and the promotion of holism as a central element.

An article on philosophies and practices analogous to bioethics among Aboriginal cultures describes a different way of perceiving health (8). The Aboriginal view is maintaining quality of life is paramount to extending life, and that achieving balance and wellness within all domains of life is commonly accepted. Palliative care encompasses ancient and modern philosophies of care by encouraging kindness and removing the possible harm of unnecessary human suffering.

Respect for autonomy is another concept that is integrally related to palliative care. In 2001, Institute of Medicine (IOM) and the National Research Council issued a report describing ways to improve care for people at the end of life (2). Although the report focused on cancer, many of the findings were applicable to individuals suffering from other terminal conditions as well. The report noted problems regarding the separation of palliative care from life-prolonging treatments. It stated that the lack of integration of these approaches caused individuals to choose between curative therapy and comfort care. Thus, an ethical dilemma is created. An individual with a terminal illness can choose either to seek a cure for their disease or to receive palliative care services. This can be perceived as an affront to autonomy. An individual's treatment options are being limited not by their free choice, but by policies that force them to choose between curative measures or palliative care. Additionally, Patrick Hill makes the argument that untreated or undertreated pain can compromise or destroy patient autonomy (9). Lisson agrees with this concept and suggests "pain is an ultimate disvalue... The more severe the pain, the more it overshadows the patient's self-defining human qualities of intelligence, autonomy, and sense of self-esteem' (10). Lisson contends that pain management is essentially a clinical-ethical issue. Patients who are suffering from pain cannot make rational autonomous decisions about their healthcare. Therefore, since individuals who are suffering are less able to actualize the concept of patient autonomy, palliative care should never be excluded from healthcare.

\section{Financial Considerations}

In 1983, Medicare established the hospice benefit, specifying a payment system and eligibility criteria. To obtain this coverage, a patient must have a terminal illness with a prognosis of 6 months or less to live if the illness runs its normal course, and the patient must be willing to forgo curative treatment (11). Medicare pays a fixed daily amount for hospice care based on four broad categories of care (12). Medicare pays approximately two-thirds of hospice services, while private insurance, Medicaid, and a variety of other sources contribute the remainder (13). Currently, there are not state and federal regulations that define the requirements of palliative care and its reimbursement structure (11). Little reimbursement is available for long-term care and palliative services outside of a hospice (14). Monies for palliative care programs depend upon how the care is provided, and often revolve around creative programs whose funding is determined by current reimbursement options. Hospital-based comfort and pain management programs are not uniformly funded and often obtain funding through other departments such as anesthesiology and mental health services. In 2001, the Centers for Medicare and Medicaid Services (CMS) issued a program memorandum that added a new specialty code for physicians who provide pain management services (11).

Thus, the system does not currently encourage palliative care coordination and management across a variety of providers and settings. A major problem with this approach is that the ethical concept of distributive justice is not achieved because of the disparities inherent in a system that does not offer palliative care in a uniform and organized way. Patients are likely to receive very different palliative services, or none at all, depending on the facility they happen to be in and their medical plan. Unfortunately, the ethical principle of justice is not served, as some patients are more likely to suffer than others. 
It is similarly unjust that a patient must forgo life-saving treatment to enhance their comfort level. It can be argued that a system which only provides comprehensive palliative care in the last 6 months of life, and only once the patient has forgone curative treatment, is encouraging the hastening of death. Ironically, what frequently occurs is just the opposite. Patients continue curative treatments to the end of their life, and consequently are denied palliative services for the majority of their disease process.

Given this dilemma, how might the idea of integrated palliative care impact the system of healthcare? There is some evidence to suggest that coordinated care decreases costs. A conference sponsored by the NIH found that the use of palliative care networks promoting pain management may reduce costs by $10-15 \%$ (15). One program at Mount Sinai Hospital found that patients who receive palliative care have shorter lengths of in-patient stays and lower pharmacy costs (16). Miller et al. claim that quality palliative and hospice care reduces needless uses of the medical system (17). Anne Reb argues, "the integration of palliative care throughout the course of illness may facilitate improved symptom management, quality of life, and continuity of care' (18). She also says that the incorporation of innovative models that encourage coordinated care should support a more cost-effective, integrated approach in delivering palliative care services. The American Academy of Nursing's Palliative and End-of-life Care Expert Panel (2001) recognized the need to integrate palliative care skills throughout the nursing care of people with acute and chronic illnesses (19). Given these claims and the fact that research estimates that Medicare benefits in the last year of life account for over a quarter of total Medicare expenditures, while Medicare spends $\sim 1.3 \%$ of its total budget on hospice services, an argument for change can be supported. In terms of cost reduction, providing palliative services may actually reduce overall costs, while improving quality of life for patients.

For systematic changes to occur in the delivery of palliative care, what steps need to be taken? Von Gunten et al. suggest three strategies for regulatory change (20). These strategies include (i) adjusting hospital payments to include essential palliative care services for hospitalized patients in pertinent Diagnostic Related Groups (DRGs); (ii) clarifying physician payment for providing palliative care by clarifying guidelines for carriers and paying for case management services; and (iii) clarifying the Medicare hospice benefit by defining the 6 month prognosis in statistical terms (20). Practice guidelines and quality indicators for palliative care are in the early stages of development (2). The development of practice guidelines and standards of care is an important contributor to costeffective, high quality care.

\section{Moral Duties}

Beauchamp and Walters state that one of the most challenging problems in ethical theory is the extent to which the principle of beneficence generates moral duties (7). Some have argued that beneficent action is a moral ideal and not an obligation.
Beauchamp and Walters write that a compromise has been drawn that says 'we are morally obligated on some occasions to assist others, at least in professional roles such as nursing, medicine, and research' (7). Therefore, an argument can be made that there is a moral obligation to provide palliative services for patients in need of this 'assistance' to minimize their suffering. I would argue that regulatory changes should be made to encompass care across the disease spectrum such that integrated palliative services are available for patients at all stages of illness. Certainly, pain, discomfort and suffering can be present at all levels of the wellness $\leftrightarrow$ illness continuum. It is insufficient to design a system of healthcare that does not fundamentally address suffering as being possible at all times. Suffering is a primary way a person knows that medical care is needed.

\section{The Role of CAM}

One of the most effective ways to treat suffering is to include CAM therapies as part of integrated palliative care. In considering the specific applications of CAM therapies for palliative care, we find several examples in the literature. CAM therapies have been shown to decrease anxiety and depression (21), to minimize pain (22) and to boost immune functioning (23). A systematic review of the evidence for the efficacy of CAM in treating pain, dyspnea, and nausea and vomiting for patients near the end of life was conducted (24). The efficacy of various CAM modalities was evaluated in 21 studies of symptomatic adult patients. The review found that acupuncture, transcutaneous electrical nerve stimulation, supportive group therapy, self-hypnosis and massage therapy may provide some pain relief for patients with cancer and/or patients who are dying. Patients with severe chronic obstructive pulmonary disease may benefit from the use of acupuncture, acupressure and muscle relaxation, with breathing retraining to relieve dyspnea (Figure 1).

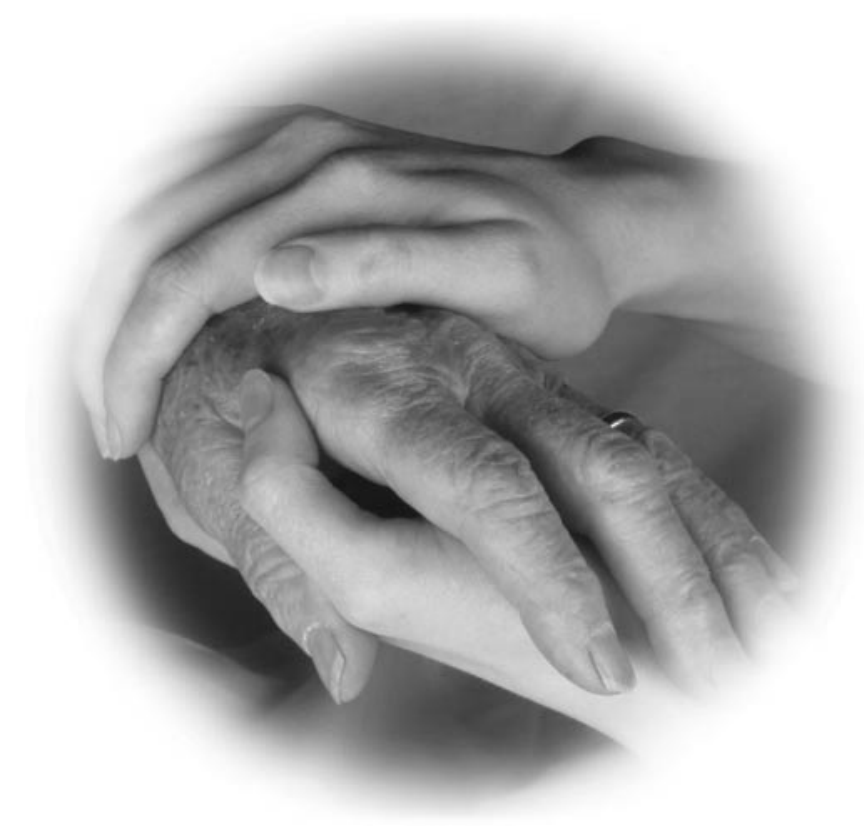

Figure 1. Gentle massage is used for patients at the end of life. 
A meta-analysis was conducted of studies that used random assignment to test the effectiveness of massage therapy (MT) (21). Mean effect sizes were calculated from 37 studies for nine dependent variables. The author found that reductions of trait anxiety and depression were MT's largest effects, with single applications of MT reducing state anxiety, blood pressure and heart rate. Multiple applications of MT were shown to reduce delayed assessment of pain. The author concludes that reductions of trait anxiety and depression follow MT, with a course of treatment providing benefits similar in magnitude to those of psychotherapy.

In an article on the long-term trends in the use of CAM therapies in the USA, researchers found that CAM use by a large proportion of the study sample was the result of a secular trend that began at least a half century ago (25). Kessler et al. explain that this trend suggests a continuing demand for CAM therapies that will affect healthcare delivery in the future. A recent article details the most commonly used CAM modalities in 2002 determined by two national surveys of CAM use by US adults (26). This article found that over one in three respondents used CAM in the past year, representing $\sim 72$ million US adults. The most popular therapies included herbal therapy (18.6\%) and relaxation techniques (14.2\%). A troubling statistic from this survey are the factors associated with highest rates of CAM use. These factors were ages 40-64, female gender, non-black/non-Hispanic race and annual income of $\geq \mathrm{US} \$ 65000$. This is of concern because we see that CAM therapies, as currently practiced, are not meeting the ethical principle of distributive justice. They are largely for the middle and upper middle class and are not used nearly as widely by people of color. An advantage of integrating CAM therapies into Western medical care as an aspect of palliative care is that these therapies will become more widely available to middle and lower income families and persons of color.

The divide that currently exists between CAM and Western medicine limits the types of CAM available for palliative care. Integrative medicine (IM) has emerged to narrow this divide and to give patients a broader range of treatment options. The Consortium of Academic Health Centers for Integrative Medicine defines IM as 'the practice of medicine that reaffirms the importance of relationship between practitioner and patient, focuses on the whole person, is informed by evidence, and makes use of all appropriate therapeutic approaches to achieve optimal health and healing' (27). Their inclusion of 'all appropriate therapeutic approaches to achieve optimal health and healing' is especially salient to the inclusion of CAM therapies in palliative care.

CAM and palliative care have in common that they are both not yet widely accepted by the Western medical community and that they are seen as being limited to 'helping patients to feel better.' What some of the new research is showing us is that this may be quite valuable indeed. In Jerome Groopman's recent book, The Anatomy of Hope, he introduces the 'body-mind connection: how input from peripheral parts is sent to the central nervous system and alters the chemistry of the brain to shape cognition and feelings' (28). He discusses the viscous neurochemical cycle that occurs when we feel a sense of hopelessness. The less hopeful, the fewer endorphins and enkephalins and the more CCK our bodies release. This causes us to feel more pain and to experience further hopelessness. One way potentially to break this cycle is by utilizing CAM therapies such as MT to shift the peripheral input sent to the central nervous system. This input could help patients to feel better and quite literally to be better as their neurochemistry shifts. This body-mind connection is additionally important because it suggests that CAM therapies may minimize dependence on pain medications such as opiates that carry some risks.

\section{Concluding Thoughts}

In looking at the frameworks supporting CAM and palliative care, we see that there are common ideological underpinnings. Cecily Saunders, who is credited with founding the palliative care movement, first coined the phrase 'total pain' in the late 1960s. She worked with patients with advanced cancer who she described as having physical, emotional, social and spiritual dimensions of suffering. For total pain relief to be possible, all of these dimensions need to be addressed. CAM and palliative care both encompass this holistic approach. CAM therapies have long understood that holism is inherent to healing. The Cartesian split between the mind and body, which has dominated Western medical thought, is pre-dated by CAM therapies that acknowledge a dynamic inter-relationship between the mind, body and spirit. Today, aspects of Cecily Saunders' theory of 'total pain' can be found in the biopsychosocial-spiritual model of care. Sulmasy articulated this model for the care of patients at the end of life (29). The model expands on the biopsychosocial model to include the spiritual concerns of patients and is a useful conceptual basis for integrated palliative care.

Integrated palliative care can be part of a philosophical movement in healthcare to see the patient and their suffering as inter-related in a dynamic exchange process that continuously influences health and well-being. We are moving beyond notions of the body as a separate entity and acknowledging its interdependent relationship to all aspects of self. If we as a society look beyond separating cures and palliation, we will come closer to incorporating compassionate care throughout the disease process. I believe there is a moral imperative to reinvigorate healthcare providers to care directly for the suffering of their patients. If we cannot ameliorate the suffering of those around us, we have forgotten what it means to be human. In that moment, have we not forgotten ourselves? To quote Albert Schweitzer: 'We must all die. But that I can save... [someone] from days of torture, that is what I feel is my great and ever new privilege' (10).

\section{References}

1. Sabatino CP. End-of-life Care Legal Trends [Internal Memorandum, 2000]. Retrieved from http://www.abanet.org/elderly/update.html. 
2. Foley KM, Gelband H. (eds.) Improving Palliative Care for Cancer. Washington, DC: National Academy Press, 2001.

3. World Health Organization. Cancer Pain Relief and Palliative Care. Technical Report Series 804.11. Geneva: WHO, 1990.

4. Chrystal-Frances E. Palliative care: a discussion of management and ethical issues. Nurs Forum 2003;38:25.

5. Tutton E. An exploration of the concept of comfort. J Clin Nurs 2003; 12:689.

6. Hoyer T. Hospice and future of end-of-life care: approaches and funding ideas. J Palliat Med 2002;5:259-62.

7. Beauchamp T, Walters L. Contemporary Issues in Bioethics. Wadsworth Publishing Company, 1999.

8. Ellerby J, McKenzie J, McKay S, Gariepy G, Kaufert J. Bioethics for clinicians: 18 Aboriginal cultures. Can Med Assoc J 2000;163:845.

9. Hill T. Freedom from pain: a matter of rights? Cancer Invest 1994;12: 438-43.

10. Lisson E. Ethical issues in pain management. Semin Oncol Nurs 1989;5:114-9.

11. Raffa C. Palliative care: the legal and regulatory requirements. Caring Magazine 2003;22:6-9.

12. Medicare Payment Advisory Commission. Report to the Congress: Medicare Beneficiaries Access to Hospice. Washington DC, 2002.

13. Williams S, Torrens P. Introduction to Health Services, 6th edn. New York: Delmar, 2002.

14. Metzger M, Kaplan KO. Transforming Death in America: A State of the Nation Report. Washington, DC: Last Acts, 2001.

15. Smith T. Technological interventions in end-of-life care. Paper presented at the NIH End-of-life Research Group Symposium. The End of Our Lives: Guiding the Research Agenda, Bethesda, MD.

16. Matherlee K. Managing Advanced Illness: A Quality and Cost Challenge to Medicare, Medicaid, and Private Insurers. National Health Policy Forum No. 779, 2002.

17. Miller S, Mor V, Gage B, Coppola K. Hospice and its role in improving end-of-life care. Апnи Rev Gerontol Geriatr 2000;20:193-223.
18. Reb A. Palliative and end-of-life care: policy analysis. Oncol Nurs Forum 2003;30:35-50.

19. American Academy of Nursing's Palliative and End-of-life Care Expert Panel. Palliative and End-of-life Care Expert Panel Meeting Minutes. Washington, DC: American Academy of Nursing, 2001.

20. Von Gunten C, Ferris F, D’Antuono R, Emanuel L. Reccomendations to improve end-of-life care through regulatory change in U.S. health care financing. J Palliat Med 2002;5:35-41.

21. Moyer CA, Rounds J, Hannum JW. A meta-analysis of massage therapy research. Psychol Bull 2004;130:3-18.

22. Norrbrink Budh C, Lundeberg T. Non-pharmacological pain-relieving therapies in individuals with spinal cord injury: a patient perspective. Complement Ther Med 2004;12:189-97.

23. Hernandez-Reif M, Ironson G, Field T, Hurley J, Katz G, Diego M et al. Breast cancer patients have improved immune and neuroen docrine functions following massage therapy. J Psychosom Res 2004;57:45-52.

24. Pan CX, Morrison RS, Ness J, Fugh-Berman A, Leipzig RM Complementary and alternative medicine in the management of pain, dyspnea, and nausea and vomiting near the end of life. A systematic review. J Pain Symptom Manage 2000;20:374-87.

25. Kessler RC, Davis RB, Foster DF, Van Rompay MI, Walters EE, Wilkey SA et al. Long-term trends in the use of complementary and alternative medical therapies in the United States. Ann Intern Med 2001;135:262-8.

26. Tindle HA, Davis RB, Phillips RS, Eisenberg DM. Trends in use of complementary and alternative medicine by US adults: 1997-2002. Altern Ther Health Med 2005;11:42-9.

27. Accessed at http://www.imconsortium.org/html/about.php on February 21 st, 2005

28. Groopman J. The Anatomy of Hope. New York: Random House, 2004.

29. Sulmasy DP. A biopsychosocial-spiritual model for the care of patients at the end of life. Gerontologist 2002;42:24-33.

Received January 26, 2005; revised February 18, 2005; accepted March 28, 2005 


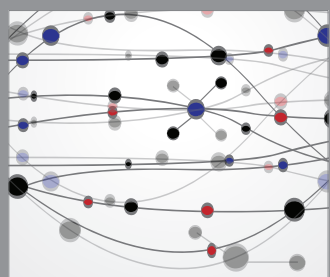

The Scientific World Journal
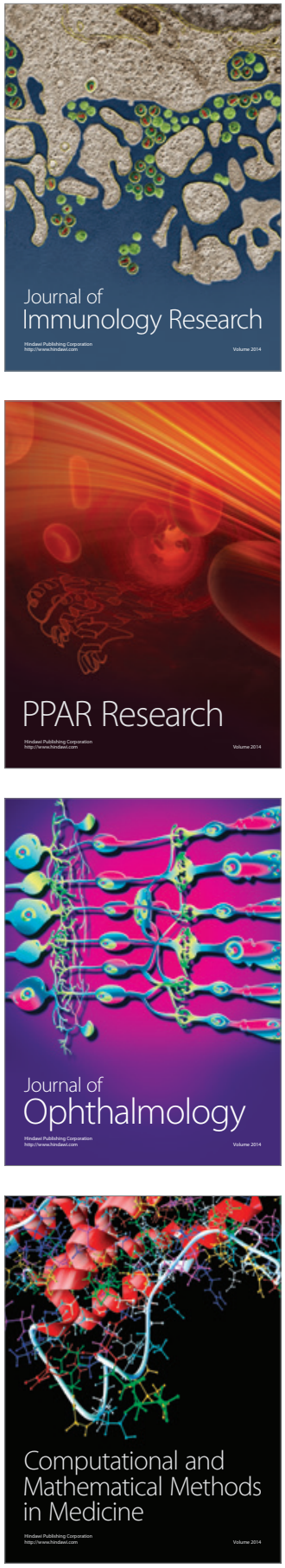

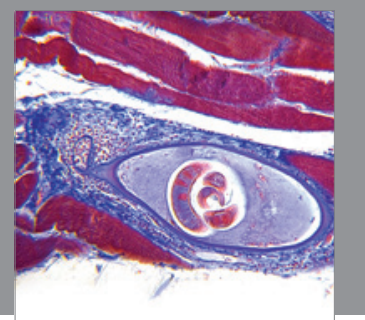

Gastroenterology

Research and Practice
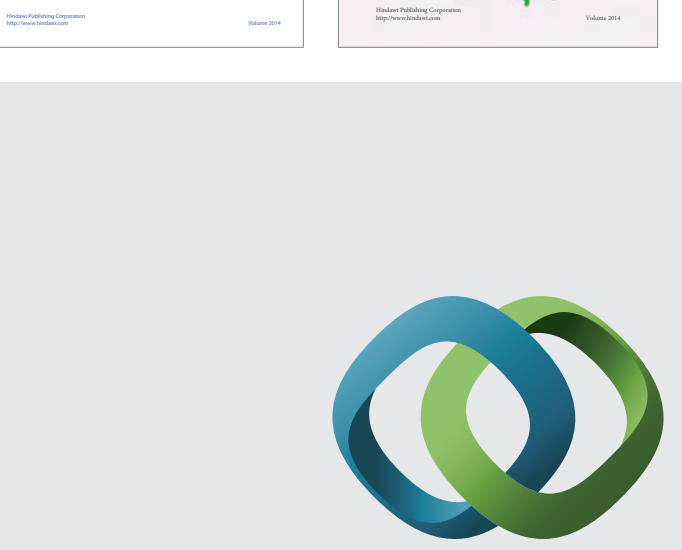

\section{Hindawi}

Submit your manuscripts at

http://www.hindawi.com
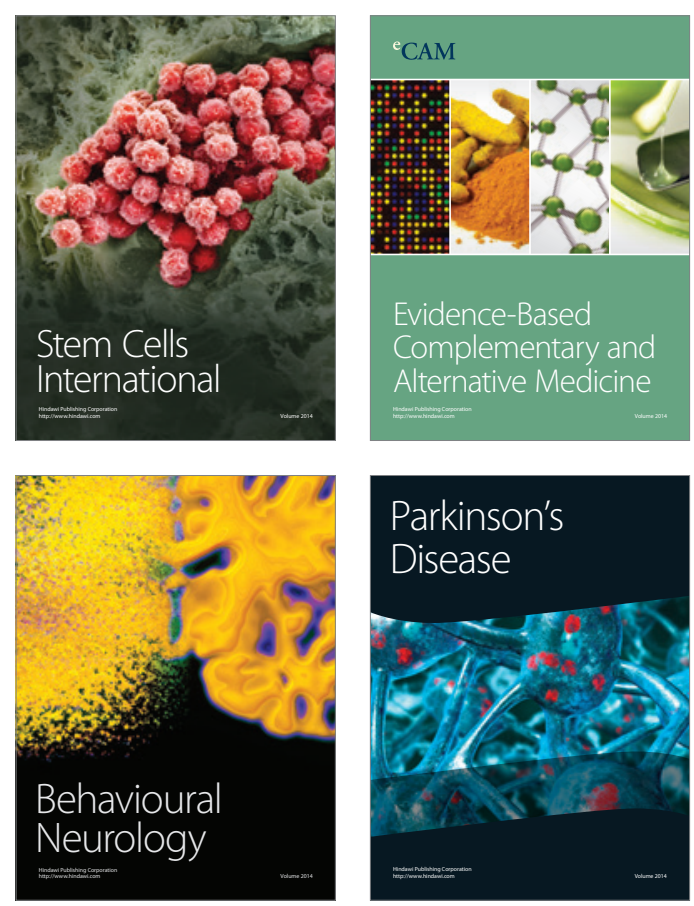

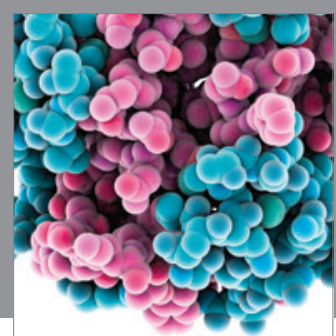

Journal of
Diabetes Research

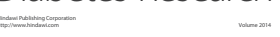

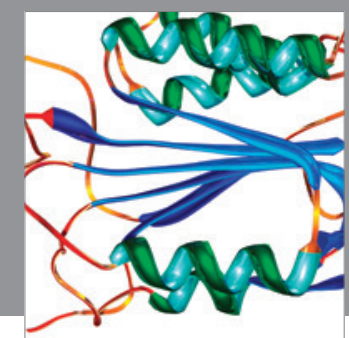

Disease Markers
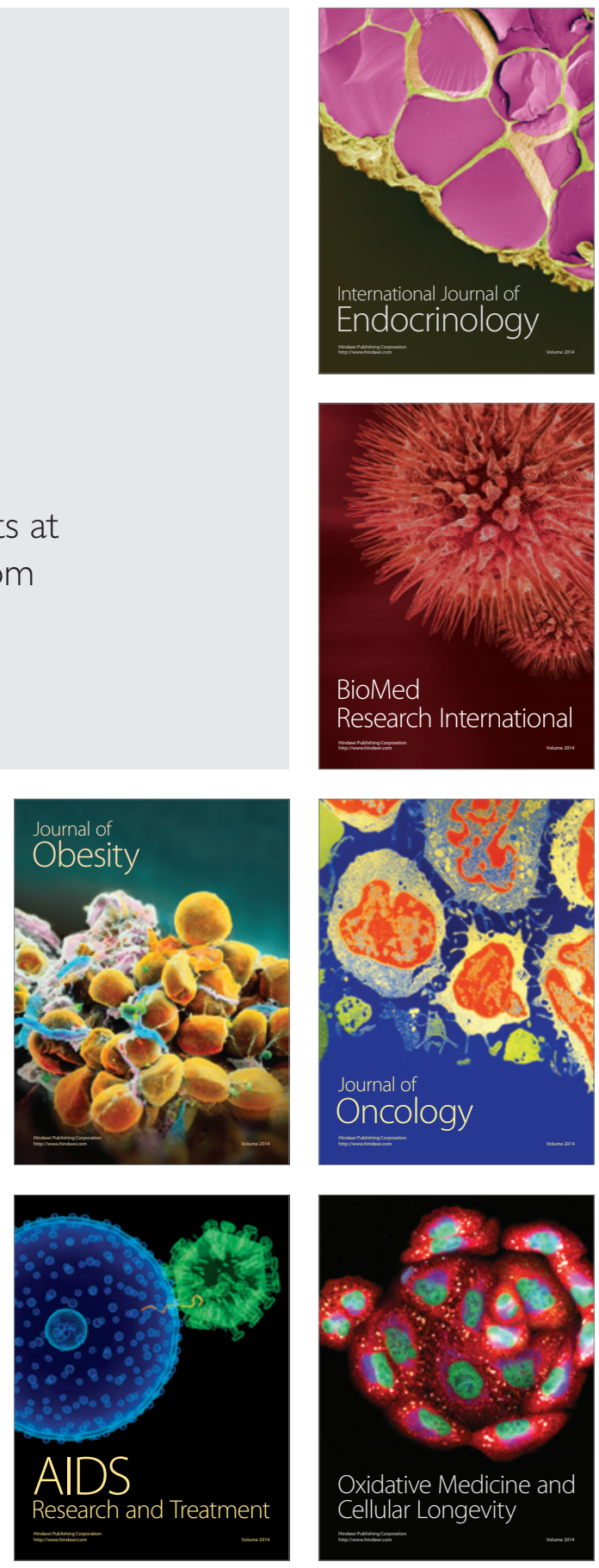